\title{
Pelvic Floor Rehabilitation to Improve Functional Outcome After a Low Anterior Resection: A Systematic Review
}

\author{
Wilhelmina S Visser, Wouter W te Riele, Djamila Boerma, Bert van Ramshorst, \\ Henderik L van Westreenen ${ }^{1}$ \\ Department of Surgery, St. Antonius Hospital, Nieuwegein, ${ }^{1}$ Department of Surgery, Isala Clinics, Zwolle, The Netherlands
}

Purpose: Impaired functional outcome is common after a low anterior resection (LAR). Pelvic floor rehabilitation (PFR) might improve functional outcome after a LAR. The aim of this systematic review is to evaluate the effectiveness of PFR in improving functional outcome.

Methods: PubMed, Embase, and the Cochrane Library were searched using the terms fecal incontinence, colorectal neoplasm/surgery, LAR, rectal cancer, anterior resection syndrome, bowel habit, pelvic floor, training, therapy, physical therapy, rehabilitation and biofeedback. Of the 125 identified records, 5 articles were included.

Results: The 5 included studies reported on 321 patients, of which 286 patients (89\%) underwent pelvic floor training. Three studies included patients with anterior resection syndrome after a LAR while the remaining studies included a series of patients after a LAR. Functional outcome was mostly assessed by using the Wexner incontinence scale. Quality of life was assessed in one study, and in three studies, rectal manometry was performed. After PFR, the functional outcome was improved in four studies, as was the quality of life.

Conclusion: This systematic review demonstrated that PFR is useful for improving the functional outcome after a LAR. The data are extracted from studies of limited quality, but the available evidence points to the effectiveness of the procedure.

Keywords: Rectal neoplasms; Fecal incontinence; Pelvic floor

\section{INTRODUCTION}

Treatment of rectal cancer has been improved by the introduction of the total mesorectal excision (TME) technique combined with preoperative radiotherapy and neoadjuvant radiochemotherapy [1]. The primary goal of the surgery is to remove all tumor tissue to achieve the best oncological result [2]. Sphincter-preserving surgery with restoration of bowel continuity to avoid a permanent

Received: May 10,2014 - Accepted: May 21, 2014

Correspondence to: Henderik L van Westreenen, M.D.

Department of Surgery, Isala Clinics, Zwolle PO box 10400, 8000 GK Zwolle, The Netherlands

Tel: :+31-38-424-2787, Fax: +31-38-424-7720

E-mail: h.I.van.westreenen@isala.nl

(c) 2014 The Korean Society of Coloproctology

This is an open-access article distributed under the terms of the Creative Commons Attribution NonCommercial License (http://creativecommons.org/licenses/by-nc/3.0) which permits unrestricted noncommercial use, distribution, and reproduction in any medium, provided the original work is properly cited. colostomy is feasible in $50 \%-80 \%$ of these patients [3]. A restorative procedure to avoid a permanent stoma is generally assumed to be preferable in terms of quality of life (QoL). However, differences in QoL between abdominoperineal resections and anterior resections are currently not established [4]. An explanation for the equivalent QoL might be the defecation disorders after sphincter-preserving surgery.

Besides oncologic results and traditional clinical outcome measures such as morbidity and mortality, functional outcome has become an important parameter for defining surgical performance after a low anterior resection (LAR) [5]. That up to $90 \%$ of such patients will subsequently have a change in bowel habit, including fecal incontinence (FI), increased bowel frequency and emptying difficulties, is widely accepted. This wide spectrum of symptoms after a resection and reconstruction of the rectum has been termed anterior resection syndrome (ARS) [3]. Previous studies revealed preoperative radiotherapy and the distance of the tumor to the anal verge as risk factors for FI after a LAR [6]. Espe- 
cially, irradiation of the anal sphincter for a low rectal tumor may impair the functional results. The results from the Dutch TMEtrial demonstrated that $39 \%$ of the patients who had a TME alone and $62 \%$ of those treated with surgery and preoperative radiotherapy were incontinent at 5 years [7].

There are currently no specific treatment options for ARS or FI. Pelvic floor rehabilitation (PFR), including pelvic floor muscle training (PFMT), biofeedback (BF) training and rectal balloon training (RBT), has been accepted as a standard technique for the treatment of FI $[8,9]$. PFMT aims to restore muscular strength, coordination and the timing of contractions. With BF, the patient gets information about the activity of the pelvic floor muscles by way of a visual display. RBT is used to increase the patient's ability to perceive the rectal distension. PFR interventions are noninvasive and inexpensive, require no sophisticated equipment and have hardly any adverse effects [10]. The aim of this systematic review is to evaluate the effectiveness of PFR in improving functional outcome after sphincter-preserving surgery for rectal cancer.

\section{METHODS}

A systematic literature search with predefined search terms was performed using the databases of PubMed, Embase, and the Cochrane Library to identify relevant articles published from 1970 to December 2013. The following keywords were used: fecal incontinence, colorectal neoplasm/surgery, low anterior resection, rectal cancer, pelvic floor, training, therapy, physical therapy, rehabilitation and biofeedback. The search strategy included the medical subject heading (MeSH) terms: fecal incontinence AND colorectal neoplasm/surgery AND (anterior resection syndrome OR bowel habit OR pelvic floor OR physical therapy OR biofeedback). A librarian assisted with the electronic search. A reference list of key articles and reviews was searched by hand to identify additional articles, which were pursued if relevant. Two reviewers (W.S.V., H.L.vW) independently screened the search results and identified the relevant articles. In event of disagreement, a consensus was reached through discussion among the reviewers.

Inclusion criteria for searching were reviews, cohort studies, case-control studies and randomized trials evaluating pelvic floor and/or biofeedback training for the treatment of functional disorders after sphincter-preserving surgery for rectal cancer. Only original articles in English, German or French were considered. All other study designs were excluded.

Two reviewers independently used a standard form to extract data from each study. The data included year of submission, country, inclusion period, number of patients, inclusion criteria, proportion of patients treated with radiotherapy, level of anastomosis from the dentate line, clinical evaluation of FI, stool frequency, description of the technique of PFR, results of functional outcome, rectal manometry and QoL. The data analysis was performed according to the Preferred Reporting Items for Systematic Reviews and Meta-Analyses (PRISMA) statement [11]. The methodological quality of the included studies was assessed by using the Methodological Index for Non-randomized Studies (MINORS) scale (maximum 24 points for comparative studies) [12]. Meta-analysis was directed towards identification of differences in incontinence scores between excercised and nonexcercised patients. Heterogeneity was tested using the $\mathrm{I}^{2}$ test (Review Manager, ver. 5.2., The Nordic Cochrane Centre, The Cochrane Collaboration, Copenhagen, Denmark). An $\mathrm{I}^{2}$ test > 50\% means major heterogeneity.

\section{RESULTS}

The search strategy identified 125 possibly relevant articles. Of these, 115 were excluded as they were irrelevant (Fig. 1). Most studies reported data regarding functional outcome after rectal cancer surgery regardless of PFR, and others evaluated the role of PFR in the treatment of FI not related to rectal surgery. Ten articles were retrieved for detailed examination and reference checking. Five of these were excluded as they were narrative reviews o were written in exceptional languages (Russian, Chinese) $[13,14]$. One study described a heterogeneous patient group including segmental colectomies, J-pouch anal anastomoses and anterior resections [15]. The five articles that met the inclusion criteria were reviewed (Table 1 ).

The 5 studies were published between 2005 and 2012, and the MINORS scale varied from 11 to 17 . Three studies $[8,16,17]$ included a group of patients with FI or ARS after a LAR and coloanal anastomosis while the remaining studies included patients not specifically suffering from FI after a LAR (Table 2). Most patients were treated with preoperative radiotherapy, and except for

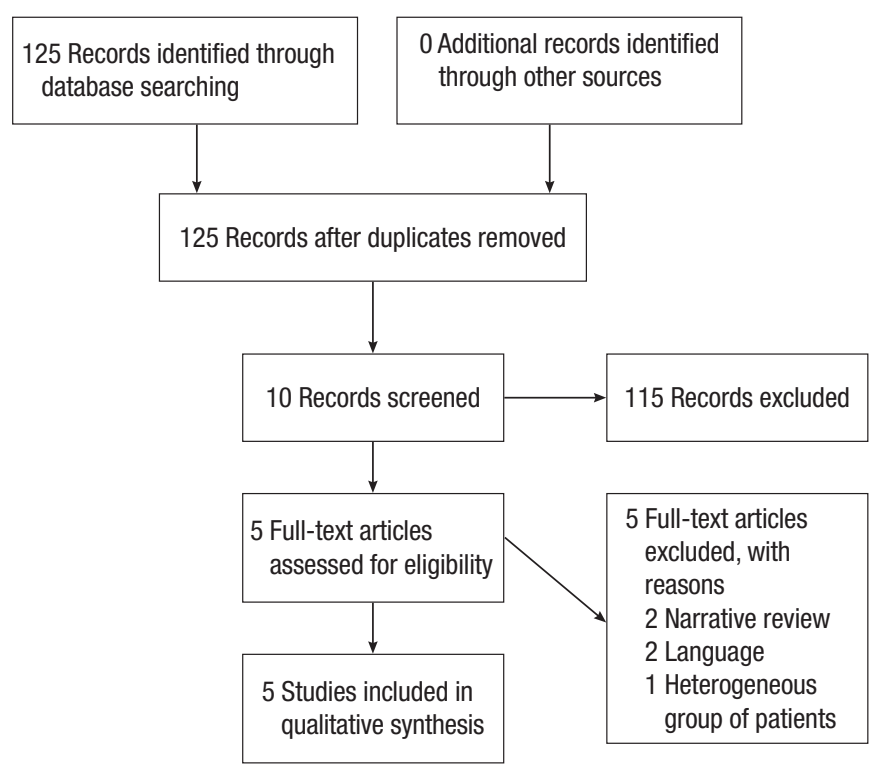

Fig. 1. Preferred reporting items for systematic reviews and metaanalyses diagram showing selection of articles for review. 
Table 1. Methodological characteristics of individual studies evaluating pelvic floor rehabilitation after a low anterior resection

\begin{tabular}{lllclc}
\hline Reference & Year & Country & Inclusion period & Study design & Methodological quality \\
\hline Allgayer et al. [8] & 2005 & Germany & June 2001-January 2004 & Prospective cohort & 12 \\
Pucciani et al. [17] & 2008 & Italy & January 2000-June 2007 & Prospective cohort & 14 \\
Liu et al. [19] & 2011 & Taiwan & $2002-2007$ & Retrospective cohort & 11 \\
Kim et al. [16] & 2011 & Korea & January 2003-December 2008 & Retrospective cohort & 12 \\
Laforest et al. [18] & 2012 & France & March 2007-February 2009 & Case control & 17 \\
\hline
\end{tabular}

Table 2. Clinical characteristics of individual studies evaluating pelvic floor rehabilitation after a low anterior resection

\begin{tabular}{|c|c|c|c|c|c|c|c|c|}
\hline Reference & $\begin{array}{l}\text { Inclusion } \\
\text { criteria }\end{array}$ & $\begin{array}{c}\text { No. of } \\
\text { patients }\end{array}$ & $\begin{array}{c}\text { No. of } \\
\text { patients with } \\
\text { preoperative RTx }\end{array}$ & $\begin{array}{l}\text { Level of anastomosis } \\
\text { from dentate line }(\mathrm{cm})\end{array}$ & Comparison & Details of PFR & $\begin{array}{l}\text { Duration of } \\
\text { treatment/follow-up }\end{array}$ & Comparison \\
\hline $\begin{array}{l}\text { Allgayer } \\
\text { et al. [8] }\end{array}$ & FI after LAR & 95 & 41 & $\begin{array}{l}\text { RTx group, } 7.6 \pm 3.1^{\mathrm{a})} \\
\text { no RTx group, } \\
10.3 \pm 4.2^{\mathrm{a})}\end{array}$ & RTx vs. no RTx & $\begin{array}{l}\text { PFMT + BF (supervised) } \\
\text { PFMT (non-supervised) }\end{array}$ & $\begin{array}{l}\text { Supervised } \\
\text { PFMT + BF: 3-weeks daily } \\
\text { Nonsupervised } \\
\text { daily, } 1 \text { hour for } 1 \text { year }\end{array}$ & $\begin{array}{l}\text { Irradiated vs. } \\
\text { nonirradiated } \\
\text { patients }\end{array}$ \\
\hline $\begin{array}{l}\text { Pucciani } \\
\text { et al. [17] }\end{array}$ & $\begin{array}{l}\text { Fl after LAR } \\
\text { or CAA }\end{array}$ & 88 & 72 & $\begin{array}{l}\mathrm{LAR}, 4.5 \pm 1^{\mathrm{a})} \\
\quad \mathrm{CAA}, 2.6 \pm 0.8^{\mathrm{a})}\end{array}$ & $\begin{array}{l}\text { Before vs. after } \\
\text { rehabilitation }\end{array}$ & $\begin{array}{l}\text { PK, BF, VR, ES } \\
\text { Different regimens: } \\
n=18: V R+B F+P K \\
n=9: E S+B F+P K \\
n=14: V R+E S+B F \\
n=35: B F+V R\end{array}$ & $\begin{array}{l}\text { PV: } 2 \text { x/wk (7 sessions) } \\
\text { BF: } 2 \text { x/day, } 20 \text { minutes for } 1 \\
\text { month } \\
\text { VR: not mentioned } \\
\text { ES: not mentioned } \\
\text { Follow-up: } 121 \pm 34 \text { days }^{\mathrm{a})}\end{array}$ & $\begin{array}{l}\text { Before vs. after } \\
\text { treatment }\end{array}$ \\
\hline Liu et al. [19] & LAR & 22 & NA & NA & $\begin{array}{l}\text { Rehabilitation vs. } \\
\text { no rehabilitation }\end{array}$ & PFMT (Kegel's exercise) & $\begin{array}{l}\text { 3-4 Times daily, follow-up: } \\
20 \pm 4.7 \text { months }^{\text {a) }}\end{array}$ & $\begin{array}{l}\text { Exercise vs. } \\
\text { nonexercise } \\
\text { patients }\end{array}$ \\
\hline Kim et al. [16] & ARS after LAR & 70 & 49 & $4.1 \pm 1.8^{\mathrm{a})}$ & $\begin{array}{l}\text { Before vs. after } \\
\text { rehabilitation }\end{array}$ & PFMT, BF, RBT & $\begin{array}{l}1 \text { x/week for } 10 \text { weeks } \\
\text { Follow-up: } 10 \text { weeks }\end{array}$ & $\begin{array}{l}\text { Before vs. after } \\
\text { treatment }\end{array}$ \\
\hline $\begin{array}{l}\text { Laforest } \\
\text { et al. [18] }\end{array}$ & LAR & 46 & 32 & $\begin{array}{l}\text { Rehabilitation group, } \\
3(0.5-9)^{\mathrm{b})} \text {; no } \\
\text { rehabilitation, } 2.5(1-9)^{\mathrm{b})}\end{array}$ & $\begin{array}{l}\text { Rehabilitation vs. } \\
\text { no rehabilitation }\end{array}$ & PFMT, RBT & $\begin{array}{l}\text { 15x 1-hour visits (1/wk) } \\
\text { follow-up: rehabilitation } \\
\text { group, } 21(8-34) \text { months }{ }^{\text {b) }} \text {; } \\
\text { no rehabilitation, } \\
22(10-46) \text { months }\end{array}$ & $\begin{array}{l}\text { Exercise vs. } \\
\text { nonexercise } \\
\text { patients }\end{array}$ \\
\hline
\end{tabular}

Values are presented as ${ }^{\mathrm{a}}$ mean \pm standard deviation or ${ }^{\mathrm{b}}$ mean (range).

$\mathrm{RTX}$, radiotherapy; PFR, pelvic floor rehabilitation; FI, fecal incontinence; LAR, low anterior resection; PFMT, pelvic floor muscle training; BF, biofeedback training; CAA, coloanal anastomosis; VR, volumetric rehabilitation; ES, electrostimulation; PK, pelviperineal kinesitherapy; NA, not applicable; ARS, anterior resection syndrome; RBT, rectal balloon training.

one study which included a higher anastomosis, the mean level of the anastomosis was below $5 \mathrm{~cm}$ from the dentate line [8]. Functional outcome was mostly assessed by using the Wexner incontinence scale (WIS) [16-18], and anorectal evaluation by manometry was performed in three studies (Tables 3, 4) [8, 16, 17]. QoL was assessed in one study by using the fecal incontinence and quality of life (FIQL) questionnaire and the Short Form 36 questionnaire (SF-36) [18], and stool frequency was assessed in three studies $[16,18,19]$. In two studies, a cohort of patients was assessed regarding functional outcome before and after a rehabilitation program $[16,17]$, and two other studies compared groups of patients with and without PFR $[18,19]$. The remaining study evaluated the role of PFR in irradiated and non-irradiated patients (Table 2) [8].

A total of 321 patients was included in the selected studies. Of these, 286 patients (89\%) underwent pelvic floor training (Table 2 ). Baseline characteristics of the patients included in the studies were relative homogeneity, including gender and type of surgery.
The mean ages of the patients varied from 55.0 years to 67.0 years. The PFR was different for all the studies (Table 2). All studies did PFMT, and four studies added BF or RBT to their training program. One study had a tailored program for each patient, leading to four different regimens [17]. Another study used PFMT as the only treatment [19]. The duration of PFR was one year or longer in two studies; the training period in the other studies varied from 10 to 17 weeks (Table 2 ).

The incontinence score (WIS, modified Cleveland incontinence score [MCIS], functional assessment of cancer therapy-colorectal questionnaire) was significantly improved after PFR in four studies $[8,16,17,19]$, and in one study no significant reduction of the WIS was observed [18]. One study showed a significantly greater improvement in WIS when BF therapy was started more than 18 months after surgery [16]. Stool frequency was decreased after PFR in two studies $[16,18]$. QoL demonstrated improved vitality and mental functioning on the SF-36 questionnaire, and rehabilitated patients suffered less from depression and had a better self- 
Table 3. Results of functional outcome from studies evaluating pelvic floor rehabilitation after a low anterior resection

\begin{tabular}{|c|c|c|c|c|c|}
\hline Reference & Assessment of functional outcome & Group & Before PFR & After PFR & P-value \\
\hline Allgayer et al. [8] & MCIS & $\begin{array}{l}\text { RTx } \\
\text { No RTx }\end{array}$ & $\begin{array}{l}7.4 \pm 2.2 \\
8.6 \pm 2.8\end{array}$ & $\begin{array}{r}8.1 \pm 3.6 \\
10.5 \pm 4.4\end{array}$ & $\begin{array}{l}<0.001 \\
<0.001\end{array}$ \\
\hline Pucciani et al. [17] & WIS & & $12.3 \pm 5.3$ & $4.9 \pm 3.9$ & $<0.050$ \\
\hline Liu et al. [19] & $\begin{array}{l}\text { FACT-C } \\
\text { Stool frequency }>3 / \text { day }\end{array}$ & $\begin{array}{l}\text { Rehabilitation } \\
\text { No rehabilitation } \\
\text { Rehabilitation } \\
\text { No rehabilitation }\end{array}$ & & $\begin{array}{r}66 \pm 11 \\
49 \pm 19 \\
4(36.4) \\
5(45.5)\end{array}$ & $\begin{array}{l}0.038 \\
1.000\end{array}$ \\
\hline Kim et al. [16] & $\begin{array}{l}\text { WIS } \\
\text { Stool frequency }\end{array}$ & & $\begin{array}{r}13.0 \pm 5.2 \\
9.4 \pm 4.5\end{array}$ & $\begin{array}{l}8.4 \pm 6.0 \\
5.8 \pm 3.3\end{array}$ & $\begin{array}{l}0.001 \\
0.001\end{array}$ \\
\hline Laforest et al. [18] & $\begin{array}{l}\text { WIS } \\
\text { Stool frequency }\end{array}$ & $\begin{array}{l}\text { Rehabilitation } \\
\text { No rehabilitation } \\
\text { Rehabilitation } \\
\text { No rehabilitation }\end{array}$ & & $\begin{array}{l}8.3(2-14) \\
9.9(5-17) \\
2.6(1-6) \\
4.0(1-10)\end{array}$ & $\begin{array}{l}0.100 \\
0.025\end{array}$ \\
\hline
\end{tabular}

Values are presented as mean \pm standard deviation, number (\%), or mean (range).

PFR, pelvic floor rehabilitation; MCIS, modified Cleveland incontinence score; RTX, radiotherapy; WIS, Wexner incontinence scale; FACT-C, functional assessment of cancer therapy-colorectal questionnaire.

Table 4. Results of manometry from studies evaluating pelvic floor rehabilitation after a low anterior resection

\begin{tabular}{|c|c|c|c|c|c|c|c|c|c|c|c|c|c|}
\hline \multirow{2}{*}{ Reference } & \multirow{2}{*}{ Group } & \multicolumn{3}{|c|}{ Max resting pressure $(\mathrm{mmHg})$} & \multicolumn{3}{|c|}{ Max squeezing pressure $(\mathrm{mmHg})$} & \multicolumn{3}{|c|}{ Rectal sensitivity (mL) } & \multicolumn{3}{|c|}{ Rectal capacity (mL) } \\
\hline & & Before & After & P-value & Before & After & P-value & Before & After & P-value & Before & After & P-value \\
\hline \multirow[t]{2}{*}{ Allgayer et al. [8] } & $\mathrm{RTX}$ & $27.3 \pm 17.2$ & - & - & $79.5 \pm 34.0$ & - & - & $44.7 \pm 1$ & - & & - & - & - \\
\hline & No $R T x$ & $33.3 \pm 17.8$ & - & & $79.5 \pm 34.1$ & - & & $43.0 \pm 13.8$ & - & & - & - & \\
\hline \multirow[t]{2}{*}{ Pucciani et al. [17] } & LAR & $20.5 \pm 10.5$ & $32.2 \pm 10.6$ & NS & $88.3 \pm 49.1$ & $107.1 \pm 79.8$ & NS & $34.6 \pm 29.6$ & $32.21 \pm 10.6$ & NS & $133.8 \pm 51.2$ & $131.0 \pm 42.8$ & NS \\
\hline & CAA & $20.1 \pm 9.6$ & $30.0 \pm 5.3$ & NS & $86.9 \pm 56.1$ & $98.8 \pm 37.7$ & NS & $33.3 \pm 11.5$ & $36.60 \pm 11.0$ & NS & $124.0 \pm 52.9$ & $143.1 \pm 34.6$ & NS \\
\hline Liu et al. [19] & - & - & - & - & - & - & & - & - & & - & - & \\
\hline Kim et al. [16] & & $39.1 \pm 11.1$ & $44.9 \pm 18.1$ & 0.100 & $136.4 \pm 45.2$ & $162.7 \pm 56.1$ & 0.006 & & & & $102.3 \pm 42.3$ & $120.3 \pm 30.6$ & 0.003 \\
\hline Laforest et al. [18] & - & - & - & - & - & - & & - & - & & - & - & \\
\hline
\end{tabular}

Values are presented as mean \pm standard deviation.

$\mathrm{RTX}$, radiotherapy; LAR, low anterior resection; CAA, coloanal anastomosis; NS, not significant.

perception on the FIQL scale [18].

One study demonstrated improved functional outcome based on anorectal pressures and rectal capacity (Table 4) [16]. Two other studies $[8,17]$ using anorectal manometry did not show any differences in the postrehabilitative rectal pressures. Pooling of the data was only possible with the data of Kim et al. [16] and Pucciani et al. [17] Both studies evaluated the functional outcome as expressed by the WIS before and after PFR. However, the I ${ }^{2}$ was $82 \%$, and reliable pooling of the data was not reasonable due to a major heterogeneity.

\section{DISCUSSION}

This systematic review demonstrated that the use of PFR is useful for improving functional outcome after a LAR. Most included studies showed an improvement regarding continence, stool frequency and QoL. The available data were extracted from studies of limited quality, and pooling of the data was not possible due to heterogeneity of the used PFR protocols and the different FI scoring systems.
The included studies showed an improvement in FI based upon the MCIS and the WIS in patients with proven FI or ARS $[8,16$, 17]. The best designed study, which was by Laforest et al. [18], did not show an improvement of the WIS, but that study included all patients after a LAR, and patients were divided into an excercised and nonexcercised group. Therefore, we would not recommend the routine use of PFR in all patients who undergo a LAR but only in patients with symptoms of FI or ARS, who might benefit most from PFR. QoL was assessed in only one study, and two questionnaires were used. Reporting the severity of ARS or FI and its impacts on QoL are of great relevance. Consistent assessment of QoL by using common definitions is necessary in future trials.

The different PFR protocols and durations of training hampered the drawing of solid conclusions from this systematic review. Furthermore, no information was available on a subset of patients who might benefit most from PFR, e.g., patients with very low colorectal anastomoses, patients with preoperative radiotherapy, or women with a history of vaginal delivery. Therefore, upcoming trials should provide this information in their patient characteristics. Several scoring systems, such as the WIS, the MCIS, the Rock- 
wood Fecal Incontinence Severity Index or the St Mark's Fecal Incontinence Grading Score, were used to assess the functional outcome after rectal cancer surgery $[20,21]$. Because FI is a major stressor in life, the Fecal Incontinence QoL scale is a condition specific QoL questionnaire and is commonly used for the assessment of ARS [22]. All of these scoring systems are very useful for assessing FI, but a meta-analysis of the several studies was not possible due to the different scorings scales. Therefore, a symptom-based scoring system for bowel dysfunction after a LAR for rectal cancer was recently developed [20]. This Low Anterior Resection Syndrome Score is related to QoL, and with it, results from different future trials can be compared. This scoring system has been validated in several European countries should the LARS score be implemented in all upcoming trials [23].

The studies included in this systematic review focused mostly on FI and stool frequency. However, the spectrum of symptoms after a LAR (ARS) included also incontinence for flatus, clustering and urgency. Specialists tend to overestimate the impact of incontinence for liquid stool and frequent bowel movements, but clustering and urgency are the symptoms that patients find the most bothersome [24]. Therefore, rectal cancer surgeons should be aware of the broad spectrum of symptoms of ARS and of the symptoms that truly matter to the patient.

Besides PFR, more therapies, such as colonic irrigation and sacral nerve stimulation, are available to treat $\operatorname{ARS}[3,25,26]$. Both therapies can lead to an improvement in functional outcome, but the patients who might benefit from these invasive therapies cannot be selected on the bases of evidence-based conclusions. Furthermore, antidiarrheal medication, food and liquid restriction are still useful for the treatment of patients with ARS.

Several questions have to be answered in future trials if the exact role of PFR after rectal surgery is to be investigated. First, should all patients after a LAR have PFR as a routine part of their treatment? Second, what type of rehabilitation protocol and what duration of therapy have to be investigated to create uniformity in the treatment? Finally, if PFR is not necessary as a routine treatment after a LAR, which patients with ARS will benefit most from PFR?

In conclusion, this systematic review demonstrated that the use of PFR is useful for improving functional outcome after a LAR. Still, solid evidence for the routine use of PFR after a LAR to improve functional outcome is lacking. Well-designed studies using uniformly-adopted scoring systems and proper selection of patients based upon reproducible criteria are needed.

\section{CONFLICT OF INTEREST}

No potential conflict of interest relevant to this article was reported.

\section{REFERENCES}

1. Kapiteijn E, Marijnen CA, Nagtegaal ID, Putter H, Steup WH,
Wiggers T, et al. Preoperative radiotherapy combined with total mesorectal excision for resectable rectal cancer. N Engl J Med 2001;345:638-46.

2. Lindgren R, Hallbook O, Rutegard J, Sjodahl R, Matthiessen P. Does a defunctioning stoma affect anorectal function after low rectal resection? Results of a randomized multicenter trial. Dis Colon Rectum 2011;54:747-52.

3. Bryant CL, Lunniss PJ, Knowles CH, Thaha MA, Chan CL. Anterior resection syndrome. Lancet Oncol 2012;13:e403-8.

4. Cornish JA, Tilney HS, Heriot AG, Lavery IC, Fazio VW, Tekkis PP. A meta-analysis of quality of life for abdominoperineal excision of rectum versus anterior resection for rectal cancer. Ann Surg Oncol 2007;14:2056-68.

5. Bloemen JG, Visschers RG, Truin W, Beets GL, Konsten JL. Longterm quality of life in patients with rectal cancer: association with severe postoperative complications and presence of a stoma. Dis Colon Rectum 2009;52:1251-8.

6. Lange MM, van de Velde CJ. Faecal and urinary incontinence after multimodality treatment of rectal cancer. PLoS Med 2008; 5:e202.

7. Peeters KC, van de Velde CJ, Leer JW, Martijn H, Junggeburt JM, Kranenbarg EK, et al. Late side effects of short-course preoperative radiotherapy combined with total mesorectal excision for rectal cancer: increased bowel dysfunction in irradiated patients-a Dutch colorectal cancer group study. J Clin Oncol 2005;23: 6199-206.

8. Allgayer H, Dietrich CF, Rohde W, Koch GF, Tuschhoff T. Prospective comparison of short- and long-term effects of pelvic floor exercise/biofeedback training in patients with fecal incontinence after surgery plus irradiation versus surgery alone for colorectal cancer: clinical, functional and endoscopic/endosonographic findings. Scand J Gastroenterol 2005;40:1168-75.

9. Lundby L, Duelund-Jakobsen J. Management of fecal incontinence after treatment for rectal cancer. Curr Opin Support Palliat Care 2011;5:60-4.

10. Bols EM, Berghmans BC, Hendriks EJ, de Bie RA, Melenhorst J, van Gemert WG, et al. A randomized physiotherapy trial in patients with fecal incontinence: design of the PhysioFIT-study. BMC Public Health 2007;7:355.

11. Liberati A, Altman DG, Tetzlaff J, Mulrow C, Gotzsche PC, Ioannidis JP, et al. The PRISMA statement for reporting systematic reviews and meta-analyses of studies that evaluate healthcare interventions: explanation and elaboration. BMJ 2009;339:b2700.

12. Slim K, Nini E, Forestier D, Kwiatkowski F, Panis Y, Chipponi J. Methodological index for non-randomized studies (minors): development and validation of a new instrument. ANZ J Surg 2003; 73:712-6.

13. Du P, Zi SM, Weng ZY, Chen W, Chen Y, Cui L. Biofeedback therapy for fecal incontinence in patients with mid or low rectal cancer after restorative resection. Zhonghua Wei Chang Wai Ke Za Zhi 2010;13:580-2.

14. Dubovyi VA. Biofeedback training in the treatment of anterior 
resection syndrome. Lik Sprava 2006;(5-6):55-60.

15. Bartlett L, Sloots K, Nowak M, Ho YH. Biofeedback therapy for symptoms of bowel dysfunction following surgery for colorectal cancer. Tech Coloproctol 2011;15:319-26.

16. Kim KH, Yu CS, Yoon YS, Yoon SN, Lim SB, Kim JC. Effectiveness of biofeedback therapy in the treatment of anterior resection syndrome after rectal cancer surgery. Dis Colon Rectum 2011;54:1107-13.

17. Pucciani F, Ringressi MN, Redditi S, Masi A, Giani I. Rehabilitation of fecal incontinence after sphincter-saving surgery for rectal cancer: encouraging results. Dis Colon Rectum 2008;51:1552-8.

18. Laforest A, Bretagnol F, Mouazan AS, Maggiori L, Ferron M, Panis Y. Functional disorders after rectal cancer resection: does a rehabilitation programme improve anal continence and quality of life? Colorectal Dis 2012;14:1231-7.

19. Liu $\mathrm{CH}$, Chen $\mathrm{CH}$, Lee JC. Rehabilitation exercise on the quality of life in anal sphincter-preserving surgery. Hepatogastroenterology 2011;58:1461-5.

20. Emmertsen KJ, Laurberg S. Low anterior resection syndrome score: development and validation of a symptom-based scoring system for bowel dysfunction after low anterior resection for rec- tal cancer. Ann Surg 2012;255:922-8.

21. Rockwood TH. Incontinence severity and QOL scales for fecal incontinence. Gastroenterology 2004;126(1 Suppl 1):S106-13.

22. Bols EM, Hendriks HJ, Berghmans LC, Baeten CG, de Bie RA. Responsiveness and interpretability of incontinence severity scores and FIQL in patients with fecal incontinence: a secondary analysis from a randomized controlled trial. Int Urogynecol J 2013;24:469-78.

23. Juul T, Ahlberg M, Biondo S, Emmertsen KJ, Espin E, Jimenez $\mathrm{LM}$, et al. International validation of the low anterior resection syndrome score. Ann Surg 2014;259:728-34.

24. Chen TY, Emmertsen KJ, Laurberg S. Bowel dysfunction after rectal cancer treatment: a study comparing the specialist's versus patient's perspective. BMJ Open 2014;4:e003374.

25. Koch SM, Rietveld MP, Govaert B, van Gemert WG, Baeten CG. Retrograde colonic irrigation for faecal incontinence after low anterior resection. Int J Colorectal Dis 2009;24:1019-22.

26. Matzel KE. Sacral nerve stimulation for faecal incontinence: its role in the treatment algorithm. Colorectal Dis 2011;13 Suppl 2: $10-4$. 